\title{
Apoio institucional e cogestão: uma reflexão sobre o trabalho dos apoiadores do SUS Campinas
}

| 1 Juliana Azevedo Fernandes, ${ }^{2}$ Mariana Dorsa Figueiredo |

Resumo: Resulta de uma pesquisa que buscou compreender as práticas de Apoio Institucional e Cogestão no Sistema Único de Saúde de Campinas-SP.

O Apoio Institucional é um dos recursos metodológicos que compõem o Método Paideia, desenvolvido por Campos para reformular a gestão. Trata-se de uma forma complementar às funçôes gerenciais que pressupõe um modo interativo, analítico e operacional: o trabalho em cogestão. Foram aplicados questionários a todos os apoiadores que consentiram em participar da pesquisa e realizados grupos focais com aqueles que preencheram os critérios de inclusão. Os dados quantitativos foram compilados em Microsoft Excel, e construiu-se uma narrativa para compor o discurso dos apoiadores nos grupos focais, posteriormente validada em um grupo de devolutiva que pretendeu, ainda, produzir novas reflexões junto ao grupo. A análise de dados foi realizada a partir da abordagem hermenêutica e referencial interpretativa da narrativa. Observou-se que, no contexto de crise instalada na cidade, os apoiadores Institucionais têm encontrado dificuldade para atuar de acordo com o que eles próprios entendem que deveria ser o trabalho de Apoio. Consideramos relevante dar continuidade ao estudo, explorando a temática sob a ótica dos serviços que são apoiados, dos gestores do nível central e dos usuários do SUS Campinas.

> Palavras-chave: gestão em saúde; método Paideia; Apoio Institucional.
1 Universidade Estadual de

Campinas. Campinas-SP, Brasil. Endereço eletrônico: fernandes. juliana@gmail.com

${ }^{2}$ Universidade Estadual de Campinas. Campinas-SP, Brasil. Endereço eletrônico: madorsa@ hotmail.com

Recebido em: 10/02/2014 Aprovado em: 11/12/2014 


\section{Introdução}

O município de Campinas-SP foi protagonista de diversas ações nos campos da Reforma Sanitária e Reforma Psiquiátrica, tendo sido considerado referência para o país e para a política pública de saúde. Desde os anos 1970, organizou uma rede de assistência expressiva (NASCIMENTO, 2007) e nos anos 2000 promoveu transformações significativas nos modelos de atenção e gestão, com a implantação do Programa Paideia Saúde da Família. Nessa época, teve início a experiência com a metodologia de Apoio Institucional, muito em voga atualmente devido aos recentes investimentos do Ministério da Saúde na formação do Apoio Integrado, que tem como referencial teórico-metodológico o Método de Apoio Paideia (BRASIL, 2012).

Este artigo resulta de uma pesquisa de mestrado que buscou compreender como está acontecendo o trabalho dos apoiadores institucionais no contexto atual da Secretaria Municipal de Campinas-SP. Fazem parte do conjunto dos objetivos, a descrição do contexto institucional e do perfil dos apoiadores atuantes na SMS de Campinas-SP, bem como a compreensão e análise sobre suas concepçōes e práticas.

O Apoio Institucional é um dos recursos metodológicos que compõem o Método Paideia, desenvolvido por Campos (2000) para reformular os tradicionais mecanismos de gestão. Trata-se de uma forma complementar as funçôes gerenciais, que altera a maneira de realizar coordenação, supervisão e avaliação do trabalho, na medida em que pressupóe um modo interativo, analítico e operacional: o trabalho em cogestão.

O objetivo do trabalho do apoiador institucional seria aumentar a capacidade dos sujeitos de refletirem e intervirem na realidade enquanto produzem bens ou serviços para outros. Busca-se alcançar maior grau de satisfação pessoal e profissional, maior envolvimento dos sujeitos no trabalho, aumento da responsabilidade diante das tarefas assumidas e a coprodução de modos de subjetivação mais solidários e comprometidos com a finalidade das instituições de saúde. O Apoio visa interferir na formação integral dos sujeitos, de modo a fazê-los repensar e recolocar-se nos planos das emoções e sentimentos, das ideias e do saber, promovendo maior capacidade nas pessoas para reconhecer e lidar com questôes singulares, que muitas vezes não estão claras ou conscientes.

Campos (2000) aponta o potencial pedagógico e terapêutico dessa proposta, na medida em que cria espaços para construção de novas subjetividades, em que, 
por meio da cogestão e invenção de novas lógicas e estruturas organizacionais, os grupos fossem adquirindo maior capacidade de análise e intervenção sobre a realidade e sobre si mesmos.

Destacamos que o Apoio não é um lugar estrutural específico nas organizações. Ele pode ou não estar conformado dentro de um organograma como cargo, como é o caso da SMS-Campinas. Mas o Apoio pode também ser exercido como uma postura metodológica, assumida tanto pelos gestores, como pelos próprios profissionais de saúde em suas relaçôes com os usuários ou outros membros da equipe (CAMPOS; CASTRO, 2014).

Onocko Campos (2003) atribui ao apoiador uma dupla função: oferecer suporte à constituição do grupo e do espaço coletivo, ao mesmo tempo em que deve estimular o grupo a alcançar seus objetivos, por meio da oferta de conceitos, categorias e recursos que sirvam de subsídio para o grupo formular suas reflexões e açôes: "Quem apoia sustenta e, ao mesmo tempo, empurra o outro. Sendo, em decorrência, sustentado e empurrado, por sua vez, pela equipe 'objeto' da intervenção" (CAMPOS, 2003, p. 87).

\section{Contexto da pesquisa}

A partir de 2001, a Secretaria Municipal de Saúde incorporou o Apoio Institucional para organização e gestão de diversas instâncias do SUSCampinas (CAMPINAS, 2004). A rede de Atenção Primária foi reorganizada em lógica semelhante à Estratégia de Saúde da Família, porém num modelo ampliado em relação ao modelo sugerido pelo Ministério da Saúde, dialogando com a dinâmica de funcionamento já instalada no município e incorporando princípios, arranjos e dispositivos que compõem o conjunto de conceitos desenvolvido por Campos em sua tese de Apoio Paideia: Clínica Ampliada, Cogestão, Equipes de Referência, Apoio Matricial, Colegiados Gestores e Apoio Institucional (CAMPOS, 2000).

Houve investimento nas ações de formação de pessoal, valorização e criação de novos espaços coletivos, com o objetivo de instituir maior democracia institucional. Nesse contexto, a equipe de supervisores dos Distritos Sanitários foi chamada a rever seu processo de trabalho e incorporar os novos arranjos e dispositivos propostos, passando a ser chamada de equipe de Apoiadores Institucionais e buscando substituir as práticas gerencialistas vigentes (CAMPOS, 2003). 
Concluída esta gestão na SMS, iniciou-se um período de grave crise na cidade e também no SUS-Campinas. O governo eleito em 2006, e reeleito em 2010, trouxe impactos negativos para o município: a taxa de pobreza absoluta em Campinas subiu 5,5\% entre os anos 2000 e 2010, e na Região Metropolitana de Campinas, o número de miseráveis aumentou em 54,4\% em dez anos (IPEA, 2013).

Para o SUS-Campinas, os impactos negativos referem-se não apenas ao desinvestimento na política de pessoal, expansão e qualificação da rede, mas numa precarização das condições de trabalho, outrora referência para a saúde no país. Campinas viveu uma crise de desabastecimento de insumos, medicamentos, fechamento de serviços, demissão de centenas de funcionários que eram contratados por meio de convênio com uma associação filantrópica, sem a devida reposição. Nesse período houve pouca clareza quanto às diretrizes para a saúde e os processos decisórios contaram com pouca participação de trabalhadores e usuários (PORTAL RAC, 2012).

Além disso, em 2011, a cidade viveu sua maior crise política, que culminou com o impeachment do então prefeito indiciado por crimes de corrupção, o afastamento do vice-prefeito e sua posterior cassação. Desde 2013, com a posse de um novo prefeito, a atual administração tem realizado convênios e contratos que terceirizam assistência e gestão dos serviços municipais. Ademais, o desabastecimento de material e medicamentos permanece, e os trabalhadores seguem sobrecarregados, sem a reposição dos colegas que deixaram o quadro e sem sucesso na tentativa de interlocução com os gestores do nível central. O vazio de formulação política para o SUS-Campinas tem desestimulado as equipes, os distritos têm-se ocupado de resolver urgências e vêm oferecendo um pacote cada vez menor de ofertas assistenciais à população (FOLHA DE CAMPINAS, 2013).

As mudanças ocorridas nos últimos anos na gestão da SMS-Campinas foram acompanhadas de certo desinvestimento político no Apoio como metodologia de trabalho. Contudo, percebe-se que o referencial Paideia se manteve incorporado no discurso e nas práticas de parte dos profissionais e gestores da rede, o que justificou o interesse e a necessidade de compreender as práticas dos apoiadores institucionais atuantes em 2013, por meio da pesquisa aqui descrita. 
Esta pesquisa se baseou nos modos de concepção da realidade e da relação sujeitoobjeto característicos da abordagem qualitativa. Nas Ciências Sociais, sujeito e objeto pertencem à mesma natureza histórica, de modo que a visão de mundo do pesquisador permeia sua aproximação do objeto e, além disso, o pesquisador é considerado como instrumento-chave para a compreensão da realidade a ser estudada (MINAYO, 2010).

Apoiamo-nos na abordagem hermenêutica crítica (GADAMER, 2003; RICOUER, 1997), entendendo-a como uma postura interpretativa que sustenta a busca pela compreensão do sentido de um texto ou, de forma geral, de um fenômeno humano. De acordo com esta abordagem, uma interpretação é sempre uma interpretação de uma interpretação, por isso infinita; e, como tal, será sempre referente a quem interpreta. Portanto, compreender um texto implica reconhecer que temos expectativas com relação ao que lemos, e atribuímos sentido ao texto também a partir dessas expectativas. Porém, uma consciência formada hermeneuticamente deve se mostrar receptiva à alteridade do texto. Essa receptividade não pressupõe neutralidade ou isenção, mas implica uma apropriação das opiniōes prévias e dos preconceitos pessoais. Então, compreender significa também lidar com nossas antecipações de sentido, mais do que buscar sentidos ocultos dos textos.

Durante o trabalho de campo, utilizamos duas técnicas para produção dos dados: questionários semiestruturados e grupos focais. $\mathrm{O}$ questionário foi elaborado especificamente para esta pesquisa e era composto por cinco blocos temáticos, contendo questões abertas e fechadas: identificação, cargo atual, formação, processo de trabalho e gestão. Realizamos os grupos focais com os apoiadores que preencheram os critérios de inclusão (ter respondido ao questionário, estar na função há pelo menos um ano e apresentar interesse em seguir participando da pesquisa). O grupo focal é uma técnica que permite a obtenção de dados a partir de encontros grupais entre pessoas que compartilham traços comuns. Caracteriza-se pelo interesse nos conhecimentos, opiniōes, representações, atitudes e valores dos participantes, e possibilita uma análise em profundidade. A interação grupal permite que o pesquisador observe como a controvérsia vem à tona e como os problemas são resolvidos, evidenciando os diferentes graus de consensos e dissensos existentes (MIRANDA et al., 2008). 
292 Essa técnica pareceu apropriada aos propósitos da pesquisa, já que interessava analisar a prática dos apoiadores do seu próprio ponto de vista, o que seria enriquecido por uma discussão em que questionamentos de uns favorecessem a participação de outros.

Nesta fase da pesquisa, buscamos aprofundar as questôes de nosso interesse e ampliar a compreensão sobre o processo de trabalho, as motivações e as dificuldades do exercício desta função, do ponto de vista dos próprios apoiadores. Após a fase de produção dos dados empíricos, propusemos outro encontro com os participantes dos grupos focais, no qual fizemos uma devolutiva dos resultados da pesquisa para, então, retomarmos nossa análise sob nova perspectiva.

A pesquisa teve aprovação do Comitê de Ética da Faculdade de Ciências Médicas da UNICAMP (no 182.352, de 18 de dezembro de 2012) e da Secretaria Municipal de Saúde. Todos os participantes assinaram o Termo de Consentimento Livre e Esclarecido, autorizando a utilização do material, resguardado o sigilo.

Para a análise e interpretação dos dados, optamos pela construção de uma narrativa, como proposto por Ricoeur (1997), isto é, a composição de um enredo que dá sentido e coerência aos acontecimentos. Onocko Campos (2008) identifica a narrativa como recurso interpretativo potente para proporcionar a elaboração de sentidos para o material produzido em pesquisas. Para a autora, há dois momentos que constituem a interpretação: a análise e a construção. Analisar significa fragmentar os fenômenos e as informações para compreendê-los; enquanto a construção seria o processo de organizar o material, costurando os fragmentos a fim de elaborar linhas de sentido que possam contribuir como saídas para os problemas encontrados.

Assim, após a transcrição do áudio dos grupos focais, construímos uma narrativa, contendo os principais núcleos argumentativos presentes nas discussões dos dois grupos focais. Decidimos construir uma só narrativa, já que se tratava de um mesmo objeto de discussão, desencadeada por um mesmo roteiro de questões. Destacamos que a narrativa foi escrita na primeira pessoa do plural, explicitando os conteúdos que haviam sido trazidos por um ou por outro grupo, no intuito que o texto refletisse traços de identidade de cada deles. Ou seja, buscamos produzir um discurso cujas linhas argumentativas foram organizadas pela pesquisadora e revelassem as singularidades de cada um dos grupos.

Para Ricouer (1997), a narrativa só tem seu sentido realizado quando é restituída ao mundo do agir, ou seja, quando a narrativa é levada ao leitor. 
Convidamos, então, todos os apoiadores que participaram dos grupos focais para

um encontro de devolutiva, em que apresentamos tanto o compilado dos dados quantitativos quanto a narrativa.

Reunir participantes de ambos os grupos focais tinha a intenção de trazer mais riqueza à discussão e possibilitar que temas que foram eventualmente abordados mais superficialmente por determinado grupo retornassem à cena, estimulado pelo que o outro grupo havia levantado numa discussão mais aprofundada. $\mathrm{O}$ grupo voltou a abordar questôes já trazidas nos grupos focais, principalmente aquelas relativas ao papel dos apoiadores e ao contexto atual da Secretaria de Saúde de Campinas, desta vez com maior profundidade e apresentando alguns novos elementos ou esclarecimentos. Assim, além da busca por compreender aquilo que nos foi dito durante os grupos focais, procuramos também produzir efeitos de intervenção ao devolver a narrativa aos participantes, para que pudessem nela se reconhecer ou não, complementando ou retificando nossa leitura e, portanto, tendo a oportunidade de recolocar argumentos e se reposicionar diante do próprio discurso.

\section{Resultados e Discussão}

Apresentaremos aqui nossas consideraçóes sobre os principais resultados da pesquisa, buscando integrar os dados produzidos por meio dos questionários com trechos da narrativa construída a partir dos grupos focais.

No período de aplicação dos questionários, 48 apoiadores faziam parte das cinco equipes dos Distritos de Saúde. No entanto, trabalhamos com os questionários preenchidos pelos 31 apoiadores que apresentaram interesse e disponibilidade em participar da pesquisa. Destes, 16 preenchiam os critérios de inclusão para seguir participando da fase dos grupos focais, sendo que o primeiro grupo contou com cinco participantes e o segundo, com 11. Já no encontro de devolutiva estiveram presentes 12 apoiadores.

Os resultados revelam que a grande maioria dos apoiadores institucionais dos Distritos Sanitários de Campinas são mulheres (81\%). A faixa etária predominante foi entre 40-49 anos (48\%), seguida pela faixa entre 50 e 59 anos $(32 \%)$. Notamos que a formação de graduação majoritária deste grupo foi em Enfermagem (36\%), tendo sido encontradas outras cinco profissões regulamentadas na área de saúde (Odontologia, Medicina, Psicologia, Terapia Ocupacional e Serviço Social) e uma da área de humanas (Ciências Sociais). 
Verificamos que todos os apoiadores participantes da pesquisa cursaram pelo menos um curso de pós-graduação. Ao considerarmos os cursos relacionados às áreas de Saúde Coletiva, Saúde da Família e Gestão em Saúde, constatamos que $77 \%$ dos apoiadores possuem pós-graduação em temas relacionados ao exercício da função de apoiador institucional, enquanto $23 \%$ cursaram pós-graduação em área afim ao seu núcleo de graduação.

O conjunto dos apoiadores participantes do estudo, portanto, constitui um grupo atuante na área há bastante tempo, inclusive tendo vários deles com perspectiva de se aposentar nos próximos anos. Como é tradição na área da saúde, encontramos um perfil feminino de trabalhadores e uma rica composição multiprofissional nos Distritos de Saúde. Além disso, trata-se de um grupo bem qualificado, com investimento na formação profissional.

Constatamos que $81 \%$ dos apoiadores trabalham 36 horas semanais, e os demais cumprem jornada de 30 horas. Verificou-se ainda que 68\% dos Apoiadores têm esta função como única atividade profissional, enquanto os demais dividem sua jornada com consultórios privados e atividades docentes. A maioria deles (74\%) tem como empregador a Prefeitura Municipal de Campinas, 13\% são contratados pela Associação Filantrópica conveniada à Prefeitura e também 13\% são funcionários municipalizados de origem da Secretaria Estadual de Saúde e Ministério da Saúde. Os apoiadores contratados por meio do convênio têm regime CLT e os demais são estatutários. Verificamos que a grande maioria dos profissionais goza de estabilidade em seu vínculo empregatício e está dedicada profissionalmente apenas às atividades como apoiador.

O tempo médio de exercício no atual cargo foi de aproximadamente 60 meses, e embora o município possua tradição em processos democráticos no campo da saúde e clara definição de critérios para ocupar cargos de gestão, verificamos que a forma de ingresso no cargo de apoiador institucional se deu predominantemente por meio de convite (83\%), chamando a atenção que apenas um apoiador tenha sido incorporado à equipe mediante processo seletivo. Consideramos que esta relação acaba traduzindo o cargo de apoiador como um cargo de confiança, o que pode comprometer a atuação deste profissional, na medida em que estabelece uma dificuldade para o enfrentamento de discordâncias, por exemplo, com o coordenador do Distrito ou outros interlocutores do nível central da SMS. Ademais, se distancia da ideia de democracia institucional, já que são designadas 
pessoas para cumprir uma função de certo modo poderosa (haja vista o poder do acesso privilegiado à informação, circulação nos espaços decisórios, além de efetivamente uma gratificação salarial) sem que esta decisão tenha sido dialogada com outros atores.

Um dado bastante relevante diz respeito às questões de formação e capacitação. A maioria dos apoiadores (68\%) nega ter recebido qualquer formação da SMS para desenvolver o trabalho de Apoio Institucional. Aqueles que afirmam ter recebido algum tipo de formação apontam que a mesma se deu por meio do Programa de Educação Permanente (ainda que façam a ressalva de que não foi uma formação específica para os apoiadores institucionais, mas para todos os gestores da SMS) ou pelas capacitações à época da implantação do Programa Paideia como diretriz da gestão municipal no início dos anos 2000. É presente nos grupos focais a percepção de que não foram capacitados para exercer esta nova função e que foram aprendendo na prática, entre erros e acertos, conforme observamos no seguinte trecho da narrativa:

Alguns de nós pensamos que a formulação proposta não se estendeu adequadamente às áreas de Urgência e Emergência e de Especialidades, de modo que aqueles que não estavam na Atenção Básica não usufruíram das capacitações propostas para o modelo. Alguns de nós acreditamos que teríamos sido abandonados pelos gestores do nível central da Secretaria de Saúde responsáveis pela implementação do Paideia, pois o modelo foi anunciado, implementado, mas com a saída do gestor da época, formulador do Paideia, ficou uma sensação de abandono e orfandade por não tê-lo ali para dar o rumo. Outros de nós discordamos, lembrando da aposta na capacidade de autonomia dos trabalhadores e gestores da Secretaria e, portanto, não entendemos que aconteceu dessa maneira. As ferramentas foram experimentadas conjuntamente e era esperado do grupo conseguir seguir adiante a despeito da troca de gestor. Admitimos que, pessoalmente, fizemos pouco investimento teórico e isso também dificultou que seguíssemos na prática do Apoio com as mudanças ocorridas no contexto.

Com relação à formação contínua para apoiar o desenvolvimento do trabalho de apoiador institucional, uma informação chama atenção: mais de $80 \%$ responderam, nos questionários, que não recebem nenhum tipo de apoio ou formação continuada para exercer sua função. Nos grupos focais, também ficou evidente o desinvestimento da SMS nesta metodologia de trabalho:

[...] lembramos que houve um período em que contamos com um analista institucional durante as reuniōes de equipe de Apoio e avaliamos que ajudava o grupo a avançar e desenvolver novos olhares diante de uma situação complexa. Hoje em dia já não temos um espaço instituído com o objetivo de olhar pros nossos processos de trabalho. O que acaba acontecendo é de utilizarmos a Reunião do Apoio, onde se 
discute de tudo, para falar algo da nossa atuação a partir de um fato, de uma situação que tomamos como analisadora, mas é bem pontual. Aliás, pensamos que a forma como é conduzida esta reunião não é boa, pois se trabalha com pouca objetividade, com muitas pautas e sem conseguir priorizar os temas.

Compreendemos que os processos de formação devem acompanhar os profissionais continuamente, proporcionando o desenvolvimento de competências técnicas, mas também éticas e relacionais. De acordo com o Método Paideia, a formação profissional deve operar tanto em processos de cognição quanto de subjetivação, na medida em que contempla ferramentas conceituais e também o desenvolvimento de uma sensibilidade para estar em contato com o outro e seu sofrimento, para trabalhar em conjunto e analisar-se permanentemente nessa relação (FIGUEIREDO, 2012).

Ao buscarmos compreender a atuação do apoiador, solicitamos que destacassem os principais recursos metodológicos que utilizam. Embora nos questionários apareçam respostas como "análise institucional", "planejamento estratégico", "educação permanente" e "rodas de conversa", nos grupos focais os apoiadores disseram que o uso desses recursos depende da demanda e que também se valem de experiências passadas:

[...] utilizamos o aprendizado de ferramentas pedagógicas que vieram com o Programa de Educação Permanente e nossas vivências como coordenadores de unidade básica. Dizendo de uma forma bem prática, alguns de nós realizamos o apoio tendo a experiência de tarefas bem incorporadas no tempo que trabalhamos como coordenadores, como a realização do estágio probatório. Da EP ficaram muitos recursos, acabamos por lembrar de certo texto ou pessoa que pode ajudar num determinado contexto de conflito, vamos juntando na nossa caixinha de ferramentas. [...] o modo como fazemos as intervençôes ressalta o respeito à condição de mútuo aprendizado quando estamos no encontro com o sujeito apoiado. Um de nós percebe que na sua prática cotidiana acaba não se utilizando ipsis litteris de determinados textos ou dinâmicas a que teve acesso, mas sabe que algo fica dessas vivências e é com esse registro que vai entrando nos processos para alguma intervenção, construindo no aqui e agora, pois a prática fala mais alto que a teoria.

Interessante notar que os apoiadores citam muito pouco os recursos metodológicos que deveriam estar no cotidiano de um apoiador e sua equipe, como a discussão de casos concretos, e o encontro regular nos espaços coletivos, buscando ouvir a demanda dos trabalhadores, construir as sínteses e ofertas.

Sobre quem seriam os sujeitos ou grupos apoiados, somente um dos apoiadores não identificou também os gestores de serviço, ou seja, os coordenadores locais, 
como sendo o sujeito que recebe mais regularmente seu apoio, tendo selecionado o trabalhador como sendo este sujeito. A maioria das respostas (42\%) considerou que o gestor é o sujeito que, na maioria das vezes, recebe o apoio, sendo seguido por $29 \%$ de respostas que apontaram gestores e trabalhadores como sendo os sujeitos apoiados e $23 \%$ incluíram usuário, gestor e trabalhador como sendo os sujeitos que, na maior parte do tempo, recebe o apoio ofertado.

Quando perguntados sobre a forma mais frequente de contato com o sujeito apoiado, $65 \%$ disseram que são os encontros presenciais. Para 16\% dos apoiadores, os encontros presenciais, por telefone e por internet, dividem igualmente a forma de contato com o sujeito apoiado. $\mathrm{O}$ uso de telefone como forma mais frequente de contato foi apontado por $13 \%$ dos apoiadores. Uma pessoa respondeu que usa mais frequentemente telefone e internet.

De acordo com a literatura, o trabalho de Apoio se realiza no encontro. Sem desconsiderar outras formas de comunicação que devem estar disponíveis, é esperado que o encontro presencial seja a marca das relações entre apoiador e sujeitos apoiados. É na roda, afinal, que se torna possível disparar reflexôes, compreender sentidos, observar e intervir sobre os "não ditos", contribuir com a instituição de espaços democráticos e negociar decisões. Observamos algumas falas no grupo focal que demonstram certo recuo e defesa dos apoiadores com relação a determinados espaços coletivos, pois se sentem sem capacidade de ação para lidar com os temas que surgem nas rodas:

[...] ontem eu tive uma reunião até sete horas da noite numa unidade, que se a Vigilância entrasse lá e fosse uma instituição privada, estaria fechada há séculos. Mas ela é uma instituição pública, então a gente fecha os olhos, não olha o bolor, não olha que o teto tá caindo na cabeça porque não tem resposta. Eu tenho vergonha. Eu falei pra colega que não tenho mais desejo de ir nesta unidade porque eu sou cobrada há anos pela mesma resposta. E por que não resolve? É um desgaste...

A Política Nacional de Humanização, exercitando do sentido do Apoio Institucional, afirma a necessidade de uma relação dinâmica entre o apoiador institucional e a equipe apoiada, apoiando à cogestão, que se destina a afirmar e a atiçar a produção de coletivos organizados (SANTOS FILHO; BARROS; GOMES, 2009). Portanto, a função do apoiador seria contribuir para a gestão e organização de processos de trabalho, na construção de espaços coletivos onde os grupos analisam, definem tarefas e elaboram projetos de intervenção. Os autores destacam que, em muitas situações, deseja-se um produto e não se tem 
dado muita importância ao modo como ele se viabiliza, reduzindo o processo de trabalho ao produto. Afirmam a importância de se reorganizarem os processos de trabalho para mudar a oferta de serviços, priorizando o modo de se discutir e articular essa reorganização em equipe, de modo que "o que fazer" não suplante o "como fazer".

Com relação à maneira como são organizados os encontros com os sujeitos apoiados, os $23 \%$ apontaram que, na maioria das vezes, os encontros são organizados a partir de demandas pontuais dos sujeitos apoiados, dos níveis de gestão responsáveis por determinado programa e a partir da pactuação prévia de encontros. Apenas 13\% afirmaram que na maior parte das vezes a relação de apoio está organizada a partir de combinação prévia com os sujeitos apoiados. Para 10\% dos apoiadores, em geral, os encontros se organizam a partir das demandas dos níveis de gestão responsáveis pela implementação de determinadas ações.

À luz das discussões ocorridas nos grupos focais, esses dados mostram que a agenda do apoiador institucional do SUS-Campinas está mais voltada a atender às demandas do nível central. São reuniões semanais nas câmaras técnicas (das áreas da saúde da mulher, da criança, da saúde mental etc.), com o colegiado de coordenadores locais, com a equipe de Apoio, ou com os setores da SMS responsáveis por projetos específicos. Os apoiadores também são chamados para participação em uma série de outras reuniōes e eventos que consideram, muitas vezes, desnecessários. Se na formulação original do Programa Paideia havia o entendimento da necessidade de uma agenda permanente de encontros entre apoiador e equipes, o que identificamos no estudo é uma agenda organizada em torno do nível central, conforme vemos na narrativa:

[...] chamamos atenção para a questão Apoio versus Gestão, refletindo sobre o quanto estamos mais próximos da gestão e não conseguimos passar para as equipes que estamos aqui para apoia-las. [...] o Apoiador vive o desafio de conseguir ser legitimado pelas equipes e efetivamente participar dos processos. Trouxemos a delicadeza da questão de estar num espaço ligado à gestão e ser demandado administrativamente tanto pelas equipes, coordenadores locais e nível central da Secretaria, ao passo que se entende que se deve fazer um papel diferente do supervisor ou fiscalizador dos trabalhadores. 
Vários de nós refletiram sobre em que medida a equipe sente que o apoiador existe para o trabalhador e não somente para a gestão. [...] a gente ainda vê muitas equipes olhando pro distrito só nos momentos de crise, na hora que precisa de alguém pra fazer uma intervenção mais hard. [...] concordamos que ficamos todos sobrecarregados e também não sabemos como dar conta das tarefas sem ficar inchando a equipe com mais e mais Apoiadores. [...] alguns de nós tivemos a impressão de que hoje não consegue fazer nada com afinco, nada com bastante cuidado, engolido por uma demanda infinita.

Cabe a reflexão sobre quem propõe e organiza o cotidiano do apoiador. Seja porque a atual gestão não tem uma proposta para esta função, seja porque a gestão demanda que o apoiador resolva questôes que não são a ênfase do trabalho de Apoio, observamos uma dificuldade em empreender ações que correspondam ao entendimento dos próprios apoiadores sobre suas atribuições. Os apoiadores revelam uma prática profissional cotidiana que não condiz com sua própria concepção, nem com o referencial teórico sobre o apoio. Observamos uma aparente submissão dos apoiadores ao modo como a gestão municipal tem lidado com este grupo e a baixa autonomia para transformar seus processos de trabalho, atropelados por uma demanda que parece não ser possível de frear.

Os principais espaços de atuação referidos pelos apoiadores foram as Unidades Básicas de Saúde (87\%), as câmaras técnicas/reuniōes de área (55\%), as reuniões de colegiado de coordenadores dos serviços locais (52\%) e espaços de controle social (36\%). Percebemos que a maior parte dos apoiadores aponta a Unidade Básica como sendo o principal espaço de atuação e nos perguntamos sobre que atuação está sendo possível. Mobilizar as equipes na reflexão do seu processo de trabalho? Transmitir informaçōes do nível central para a "ponta"? Receber as demandas do coordenador local para resolução de problemas ligados a infraestrutura, desabastecimento e insuficiência de quantidade de profissionais? De acordo com os questionários, os assuntos mais abordados no cotidiano de trabalho dos apoiadores, segundo a percepção dos próprios, apontam para as últimas hipóteses. Os temas mais frequentemente abordados citados, por ordem, foram: 1) recursos humanos (dimensionamento, insuficiência de número de profissionais, qualificação do trabalhador); 2) estrutura física dos serviços, materiais e insumos (má qualidade, insuficiência, desabastecimento); 3) processo de trabalho; e 4) conflitos nas relações interpessoais. 

dia e a finalidade do trabalho do apoiador. Ao recuperarmos o referencial teórico que dá indicações sobre possíveis Núcleos Temáticos a percorrer no trabalho de Apoio (CAMPOS, 2000), perceberemos a fragilidade da prática atual, centrada em questôes que pouco dialogam com a expertise do apoiador e que, como pudemos perceber no grupo focal, também não são colocadas em análise. Ao contrário, reafirmando um modelo de gestão taylorista, o que observamos foi uma longa lista de reclamações e a distribuição de tarefas a serem cumpridas entre as equipes de Apoio dos Distritos:

Mas aí te botam no colo e você tem que fazer. A mesma coisa acontece quando chega alguém dizendo que não tem passe pra mãe amamentar lá, mas aí é da saúde ou da assistência? É da Assistência. Mas a Assistência diz que não tem perna, e aí você tira do bolso. Então, tem coisas que a gente sabe que não é nossa, ou pelo menos não é só nossa, mas não tem uma discussão intersecretarias, entre as pessoas que viabilizam, e acaba ficando no colo. E tem coisas que quando te põem no colo, te incomodam e aí você fala: não dá pra não resolver. E aí você vai atrás, mesmo sabendo que aquilo não era seu.

Questionamos como é trabalhar num modelo de Atenção Básica num município que se diz "heterogêneo" em suas organizações, sendo frequente encontrarmos unidades de saúde que operam segundo a lógica da territorialização e outras não, contando com agentes comunitários de saúde e outras não, contemplando visita domiciliar em sua programação e outras não, entre outros. Um município que não consegue afirmar uma diretriz para Atenção Básica fica mais facilmente engolido por programas e políticas do Ministério da Saúde que podem não fazer sentido para o contexto local, por exemplo. Transforma-se na atribuição do apoiador implantar as redes de atenção em nome de uma adequação à recomendação ministerial, mais do que ajudar a formular as políticas locais e seu diálogo com a diretriz nacional, considerando todo o saber que dispõe sobre seu território e os problemas da população.

Qual é o caminho a seguir? O foco principal é na Atenção Básica? Se é, o que nós enquanto apoio temos que saber pra conduzir isso? Porque é diferente você entender da saúde mental, do adulto, da criança dentro de uma lógica de programas e não de constituição de rede. Isso se perdeu na Secretaria, vem Rede Cegonha e implanta, depois vem a RAPS, uma salada mista...

Qual é o modelo hoje? O Apoio veio como parte de outro modelo, não é à toa que a gente fica buscando alternativas dentro das possibilidades que tem. Quando não tem modelo, tudo cabe, fica todo mundo tentando encontrar soluções individuais, que é o que tem mais sentido pra você no plano individual. 
Mesmo no nível regional, vemos a grande dificuldade e pouco enfrentamento à questão da atenção especializada e sua relação com a Atenção Básica. Por exemplo, toda oferta de especialidade médica, em Campinas, se dá por meio de agendamento em um sistema on line. $\mathrm{O}$ usuário de um bairro da região norte pode ser encaminhado para um especialista que atende na região sudoeste ou qualquer outra, conforme a vaga apontada pelo sistema. Além disso, não há qualquer garantia no sistema de referência ou contrarreferência para os casos que saem da unidade e vão para o especialista, visto que não há um profissional (ou um grupo organizado) de referência na atenção secundária para a unidade, prejudicando imensamente a lógica da coordenação clínica dos casos. Tampouco há organização de uma lógica regionalizada para a realização do Apoio Matricial, na relação entre Atenção Básica e Especializada. No entanto, não verificamos esta relevante temática como sendo objeto do trabalho do Apoiador.

Abordamos junto aos apoiadores, tanto nos questionários quanto nos grupos focais, sua concepção a respeito do que é ser apoiador institucional. As respostas mais frequentemente encontradas traduziam o apoiador institucional como sendo aquele que acompanha, articula e/ou facilita o trabalho em saúde. Responderam também que o apoiador estimula reflexões, promovendo mudanças no processo de trabalho. Foi citada ainda a definição de apoiador como um cargo de gestão, que cumpre função de elo entre o nível central e o gestor local (coordenador de unidade básica ou de outro serviço do território):

[...] compreendemos que o apoiador institucional tem função estratégica, pois auxilia a fazer as articulaçôes necessárias e facilita processos, contudo, entendemos que nosso cotidiano é recheado de demandas sobre as quais não temos capacidade resolutiva, pois dizem respeito a outros atores com outra ordem de governabilidade para lidar com elas. [...] um de nós lembrou que não temos autonomia financeira, nem legal-jurídica, não somos diretores ou chefes de setor, mas somos técnicos que temos papel fundamental para os desdobramentos das açôes. Entendemos que o apoiador se tornou um grande fazedor de tarefas e [...] revelamos nosso desgosto com esta situação, que põe em xeque a legitimidade do Apoiador Institucional, uma vez que o mesmo não consegue dar uma série de respostas requeridas e que não são de sua alçada responder.

Refletimos aqui sobre o que caracterizaria a função Apoio, senão apoiar um coletivo organizado para produção. De acordo com os participantes deste estudo, o processo de trabalho dos apoiadores não tem se pautado prioritariamente nesta ação, e tem-se configurado como uma engrenagem na correia de transmissão das 
informações e demandas do nível central para a "ponta" e atuando em situações tidas como urgentes por esta gestão, como pudemos observar acima. Poderíamos afirmar que os apoiadores chegam a questionar a viabilidade do Método de Apoio para o momento presente. Revelam que os espaços de discussão são cada vez mais raros e a interlocução entre os atores da SMS, quando ocorre, tem sido improdutiva. Por outro lado, revelam seu desejo e satisfação quando conseguem estar, de fato, em função de Apoio às equipes:

Nos dois grupos, acreditamos que grande parte do cotidiano de trabalho como apoiador tem sido de muito apagar incêndio, de tentar resolver as demandas urgentes e tem sobrado pouco tempo para reflexão, para debates e para o trabalho generalista. Alguns de nós lamentamos esta realidade e reforçamos o quanto é gratificante quando é possível entrar no processo de trabalho das equipes e não apenas responder ao nível central ou a questōes ligadas a infraestrutura, materiais e pessoal nas unidades. Pensamos, no segundo grupo, que criamos maiores condiçôes disso acontecer quando cuidamos de manter espaços coletivos com regularidade, tais como as reuniōes de saúde mental ou de enfermagem, por exemplo, em que você troca mais horizontalmente e com frequência, diminuindo a sensação de só estar para apagar incêndio.

Os apoiadores parecem aguardar uma diretriz externa ou uma liderança que lhes impulsione a trabalhar com o método, como ocorreu no passado. Embora seja sabido o contexto de grave crise que atravessa o município, não observamos os apoiadores ocupando os espaços que poderiam, seja em defesa do trabalho em cogestão, menos autoritário, seja em defesa da própria política pública de saúde e que questione o modus operandi da atual gestão. Reforçam que a atual administração não lhes explicita qual é o modelo de gestão adotado e o que espera do apoiador:

Nós, nos dois grupos, pedimos por uma devolutiva dessa pesquisa e alguns de nós no segundo grupo sugerimos que, a partir daqui, pudesse ser feita alguma movimentação que colocasse a Secretaria de Saúde diante da temática, a fim de entender qual é o papel de Apoiador esperado pela atual gestão. No segundo grupo, alguns de nós pensamos que o nível central não tem ainda ideia do que seja o trabalho do apoio, e que se utiliza da gente enquanto mata-burro, pra decifrar projetos, pra ficar junto e ajudá-los, até pelo fato de que eles próprios não sabem o que eles têm que fazer.

Nossa percepção é a de um grupo de apoiadores trabalhando da maneira que entendem como sendo a possível diante do atual contexto. Não parece haver um projeto para o Apoio entre os próprios apoiadores. Certamente, não há projeto invulnerável a qualquer que seja o contexto, porém, faz-se necessária a luta política para a condução e eventual correção de rumo na trajetória do Apoio. 
Vemos que o modelo de democracia institucional proposto pelo Método Paideia, e a figura do apoiador institucional para operar esta lógica, não está em debate. $\mathrm{O}$ apoiador hoje não está conectado com as demais questões que o método propõe. É um desafio manter uma práxis que dialogue com os temas das relações horizontais, da gestão participativa, da coprodução de sujeitos e coletivos com maiores coeficientes de autonomia, enquanto há uma gestão central alheia a estas propostas. Não é imotivada nossa percepção de um estado de desânimo e certo imobilismo entre os apoiadores, cada vez menos protagonistas de suas ações e sendo requeridos a desempenhar funções que não consideram como sendo aquelas que outrora trouxeram encantamento.

\section{Conclusões}

Destacamos que, ao buscar compreender como está incorporada a concepção de Apoio Institucional entre os apoiadores do SUS-Campinas, mais do que confirmar ou não se eles trabalham de acordo com a teoria Paideia ou com o modelo implementado no passado nesta cidade, pretendíamos analisar como é, afinal, sua prática hoje. Para tanto, descrevemos o atual contexto institucional, além do perfil dos apoiadores que hoje compõem as equipes de Apoio Institucional dos Distritos Sanitários de Campinas.

Neste percurso, consideramos que, embora se sustente a nomenclatura de apoiador e muitas referências a como deveria se dar o trabalho de Apoio Institucional, o grupo de apoiadores do SUS-Campinas afirma outra prática cotidiana, organizada em torno da resolução de questôes administrativas e burocráticas, na maior parte do tempo. O grupo aponta ainda que desconhece o que é esperado, por parte da gestão central do SUS-Campinas, do trabalho do apoiador. Talvez não haja uma expectativa da atual administração a esse respeito, talvez justamente a intencionalidade seja a de desmontar o que se produziu anteriormente no SUS-Campinas, mas é importante ressaltar que a postura passiva que observamos acaba por alimentar uma gestão autoritária e descomprometida com a política pública de saúde.

Consideramos importante avaliar a questão da coerência de um projeto de gestão. Em 2001, quando a Secretaria Municipal de Saúde incorporou o referencial Paideia na organização e gestão de diversas instâncias do SUSCampinas, havia um projeto maior, sustentado inclusive pelo prefeito da cidade, 
que tinha diretrizes bem definidas: havia uma aposta clara na Atenção Básica, nas Equipes de Referência, na Clínica Ampliada e no modelo de cogestão. A figura do apoiador institucional estava nesse contexto, como um ator importante para operar as lógicas participativas em substituição aos padrões de cobrança e fiscalização que havia com os supervisores, coproduzindo coletivos com maior capacidade de compreender a realidade para intervir criticamente e gerar maior democracia institucional.

Deslocar apenas uma peça, o apoiador, de toda essa sofisticada teia de formulação e atirá-la a um contexto estéril não poderia produzir os efeitos esperados em outro momento histórico. Atentamos para a possibilidade de cair num idealismo do passado e de se transferir a responsabilidade por não existir um projeto para o Apoio Institucional. Preferimos apostar na tradição militante de Campinas na construção e consolidação da política pública de saúde e acreditar que, enxergando criticamente os limites que o Método Paideia encontra no atual contexto, haja uma organizada movimentação que contribua para reverter a situação do SUS-Campinas.

Apontamos, por fim, que esta pesquisa se propôs a considerar apenas a perspectiva dos apoiadores institucionais do SUS-Campinas falando sobre suas práticas. Recomendamos, em consonância com o pedido dos próprios apoiadores, que este estudo tenha continuidade, abordando a temática do Apoio Institucional sob a perspectiva das equipes de referência, dos gestores distritais e do nível central, e dos usuários dos serviçosi.

\section{Referências}

BRASIL. Ministério da Saúde. Secretaria-Executiva. Diretrizes do Apoio Integrado para a qualificação da gestão e da atenção no SUS. Brasília: Ministério da Saúde, 2012.

CAMPINAS. Prefeitura Municipal de Campinas, 2004. Programa Paideia: as Diretrizes da Secretaria Municipal de Saúde - Gestão 2001-2004. Disponível em <http://www.campinas. sp.gov.br>. Acesso em: 15 dez. 2013.

CAMPOS, G.W. de S. Saúde Paidéia. São Paulo: Hucitec, 2003, 185p.

. Um método para análise e cogestão de coletivos. São Paulo: Hucitec, 2000. 236p.

CASTRO, C.P.; CAMPOS, G.W. de S. Apoio Institucional Paideia como estratégia para educação permanente em saúde. Trab. educ. saúde, v. 12, n. 1, p. 29-50, 2014. 
FIGUEIREDO, M.D. A construção de práticas ampliadas e compartilhadas em saúde: Apoio Paidéia e formação. 2012. 341p. Tese (Doutorado em Saúde Coletiva) - Departamento de Saúde Coletiva, Universidade Estadual de Campinas, Campinas, 2012.

FOLHA DE CAMPINAS, 2013. Disponível em <http://www.mcjeditora.com.br/ portal/2013/04/restricao-de-exames-e-filas-agravam-crise-na-saude-publica-emcampinas>. Acesso em: 20 jan. 2014.

GADAMER, H.-G.G. Verdade e método I: traços fundamentais de uma hermenêutica filosófica. Petrópolis: Vozes, 2003. 631p.

INSTITUTO DE PESQUISAS ECONÔMICAS APLICADAS. Pobreza e riqueza em Campinas e Região: breve balanço da primeira década do século 21. Documento de Análise Técnica. Brasília: IPEA, 2013.Disponível em <www.ipea.gov.br>. Acesso em: 10 jan. 2013. MINAYO, M.C.S. (Org.). Pesquisa Social: teoria, método e criatividade. Petrópolis: Vozes, 2010.

MIRANDA, L. et al. Dos grupos focais aos grupos focais narrativos: uma descoberta no caminho da pesquisa. In: ONOCKO-CAMPOS, R. et al. (Orgs.). Pesquisa avaliativa em saúde mental: desenho participativo e efeitos de narratividade. São Paulo: Hucitec, 2008. p. 249-277.

NASCIMENTO, E.L. et al. O município de Campinas e a organização da Secretaria Municipal de Saúde. Revista da Ciência Médica, v. 16, n. 3, p. 161-173, 2007.

ONOCKO-CAMPOS, R. O exercício interpretativo. In: ONOCKO-CAMPOS, R. et al. (Orgs.). Pesquisa avaliativa em saúde mental: desenho participativo e efeitos de narratividade. São Paulo: Hucitec, 2008, p. 278-299.

. O planejamento no labirinto: uma viagem hermenêutica. São Paulo: Hucitec, 2003.

PORTAL RAC, 2012. Disponível em: <http://portal.rac.com.br/noticias/index_teste. php?tp = campinas-e-rmc \&id $=/ 118503 \&$ ano $=/ 2012 \&$ mes $=/ 02 \& \mathrm{dia}=/ 25 \&$ titulo $=/$ saude em-crise-preve-cortar-r-25-mi-do-orcamento>. Acesso em: 10 jan. 2014.

RICOUER, P. Tempo e narrativa. Campinas: Papirus, 1997.

SANTOS FILHO, S.B.; BARROS, M.E.; GOMES, R.S. A Política Nacional de Humanização como política que se faz no processo de trabalho em saúde. Interface. Botucatu, v. 13, n. 1, p. 603-613, 2009.

\section{Nota}

${ }^{i}$ J.A. Fernandes participou da concepção do artigo, redação, análise e interpretação dos dados, e aprovou a versão final a ser publicada. M.D. Figueiredo realizou a revisão crítica relevante do conteúdo intelectual e aprovou a versão final a ser publicada. 


\section{Abstract}

\section{Institutional Support and co-management: a reflection on the work of institutional supporters of SUS Campinas}

This paper comes from a study that sought to understand the practices of Institutional Support and co-management in the Unified Health System (SUS) of Campinas-SP. The Institutional Support is one of the methodological resources that make up the Paideia method, developed by Campos to reshape management. This is an additional way to managerial functions that assumes an interactive, analytical, and operational mode: working in co-management. Questionnaires were applied to all supporters who agreed to participate and focus groups were held with those who met inclusion criteria. Quantitative data were compiled in Microsoft Excel, and built a narrative to make the speech of supporters in the focus groups, subsequently validated in a feedback group that intended to produce new insights with the group. Data analysis was performed from the hermeneutic approach and interpretation of the narrative framework. It was observed that in the context of crisis in the city, institutional supporters have found it difficult to act according to what they believe should be the work of support. We consider it important to continue the study, exploring the theme from the perspective of services that are supported, from the central level managers and users of SUS-Campinas.

> Key words: health management; Paideia method; Institutional Support. 